\section{GREGORY W. RUTECKI, MD, Section Editor}

Hadrian Mendoza, MD

Department of Pediatrics,

Emory University School of Medicine,

Atlanta, GA

Ian Odell, MD, PhD

Department of Dermatology,

Yale School of Medicine,

New Haven, CT

\section{Justin Goodwin, MS}

Department of Epidemiology of Infectious Diseases, Yale School of Public Health,

New Haven, CT

Jennifer McNiff, MD

Department of Dermatology and

Department of Pathology, Yale School

of Medicine, New Haven, CT
Jeffrey Gehlhausen, MD

Department of Dermatology,

Yale School of Medicine,

New Haven, CT

Karthik Gnanapandithan, MD

Department of Internal Medicine

Mayo Clinic, Jacksonville, FL

\title{
New bullous lesions in a 72-year-old woman
}

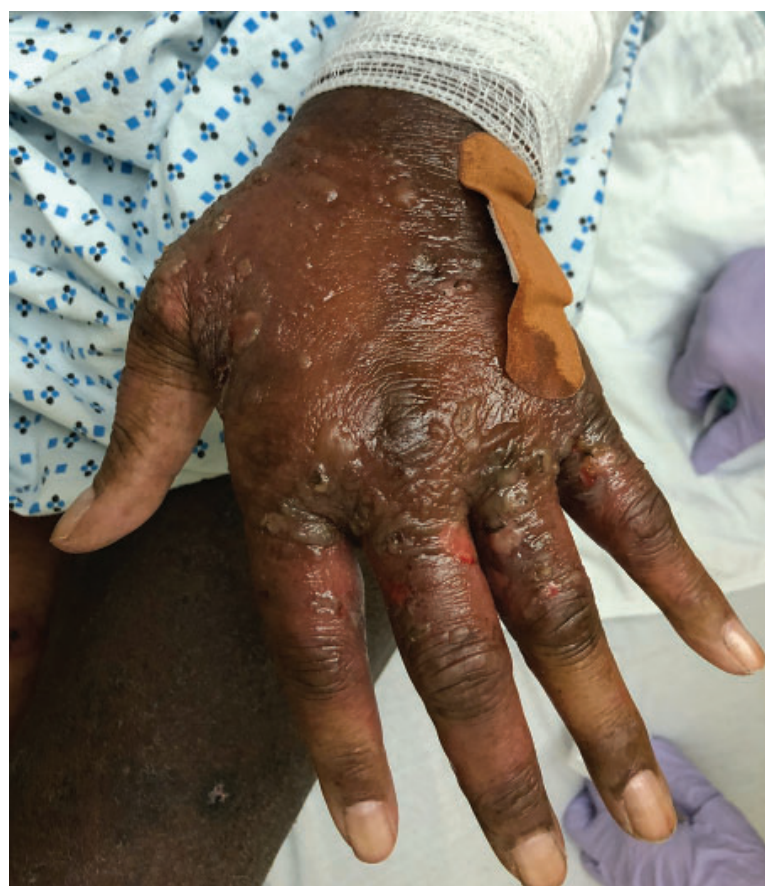

Figure 1. The dorsum of the left hand with tense bullae and erosions.

72-Year-Old WOMAN With a History of $A$ psoriasis, chronic lower-extremity edema, and hypertension presented to the emergency department with 2 days of a progressive painful blistering rash primarily involving her hands. She had previously experienced infrequent episodes of herpes labialis and symptoms of fatigue and myalgia. She denied any recent travel or contact with chemicals. She was taking losartan $50 \mathrm{mg} /$ day and furosemide $20 \mathrm{mg} /$ day, which had been prescribed 2 months before for hypertension and peripheral edema.

doi:10.3949/cjm.88a.20180

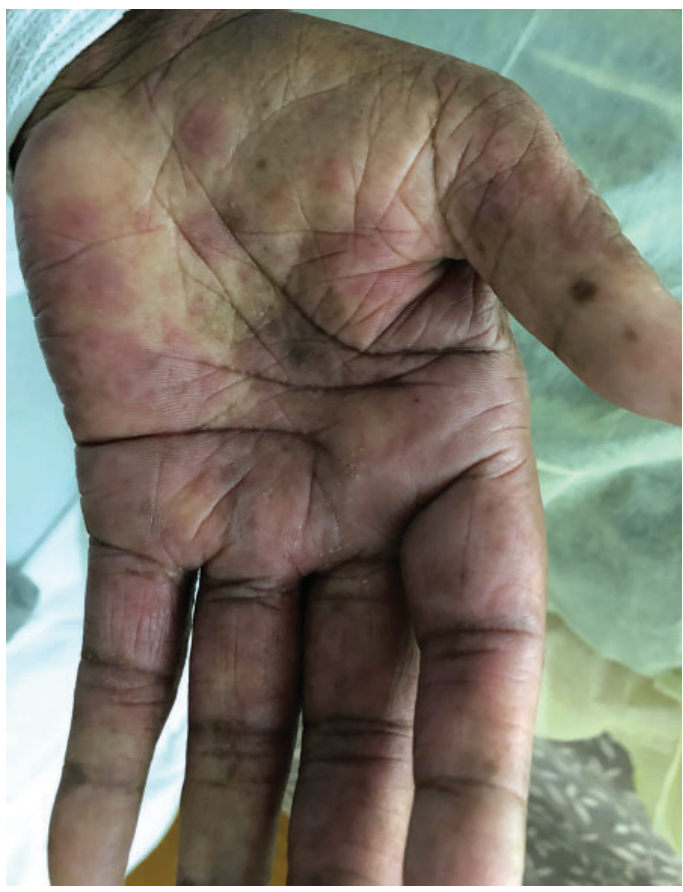

Figure 2. The left palm with red, atypical target lesions.

\section{INITIAL EVALUATION AND MANAGEMENT}

Her temperature was $98.5^{\circ} \mathrm{F}\left(36.9^{\circ} \mathrm{C}\right)$, heart rate 107 beats per minute, blood pressure 180/83 mm Hg, respiratory rate 18 breaths per minute, oxygen saturation $100 \%$ on room air, weight $69 \mathrm{~kg}(152 \mathrm{lb})$, and body mass index $26 \mathrm{~kg} / \mathrm{m}^{2}$.

Skin lesions were present at several sites. The dorsum of her hands had dozens of clear vesicles $0.5 \mathrm{~cm}$ to $2 \mathrm{~cm}$ in diameter and bullae (Figure 1), and her palms had red target lesions $0.5 \mathrm{~cm}$ to $1 \mathrm{~cm}$ (Figure 2). Her thighs had red plaques that had central scale and were bordered by vesicles. Her left lower lip had 2

\section{A woman \\ with psoriasis, chronic edema, and hypertension presented with a progressive, painful blistering rash}




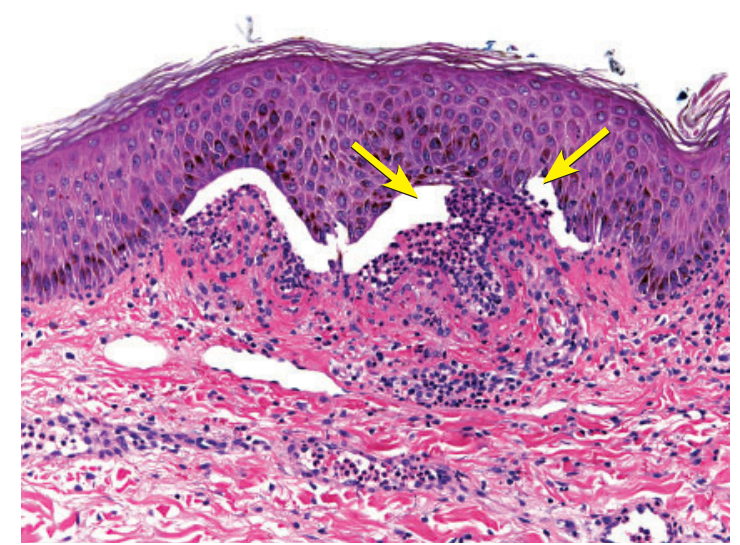

Figure 3. Biopsy from the left hand was significant for subepidermal bullae (arrows) with neutrophils.

flaccid vesicles $3 \mathrm{~mm}$ to $4 \mathrm{~mm}$. No ocular or anogenital lesions were seen. The lesions were negative for the Nikolsky sign (separation of the epidermis from the dermis).

Her lungs were clear to auscultation. Although her heart rate was elevated, the rhythm was regular, and there were no murmurs, rubs, or gallops. Her abdomen was soft and nontender to palpation. She was alert and oriented, and her behavior was appropriate.

\section{Drugs linked to bullous pemphigoid include etanercept, sulfasalazine, furosemide, and penicillin}

\section{Laboratory testing and histopathology}

Laboratory tests taken while she was in the emergency department were notable for the following results:

- White blood cell count $12.1 \times 10^{9} / \mathrm{L}$ (reference range $\left.4.0-10.0 \times 10^{9} / \mathrm{L}\right)$

- Eosinophils 2.3\% (0.0-7.0\%)

- Absolute eosinophil count $0.3 \times 10^{9} / \mathrm{L}$ $\left(0.0-1.0 \times 10^{9} / \mathrm{L}\right)$

- Hemoglobin 10.4 g/dL (12.0-18.0 g/dL)

- Mean corpuscular volume $78.7 \mathrm{fL}$ (78.0 $94.0 \mathrm{fL}$ )

- Platelet count $359 \times 10^{9} / \mathrm{L}(140-440 \times$ $10^{9} / \mathrm{L}$ )

- Erythrocyte sedimentation rate $86 \mathrm{~mm} / \mathrm{h}$ (0-20 mm/h)

- C-reactive protein $80 \mathrm{mg} / \mathrm{L}(<10 \mathrm{mg} / \mathrm{L}$ ). She was admitted to the hospital and treated empirically with famciclovir for a presumed herpes infection. Further evaluations returned negative results for antibodies to bullous pemphigoid 180 (BP180) and 230 (BP230) and collagen type VII in the serum. Polymerase chain reaction testing was negative for herpes

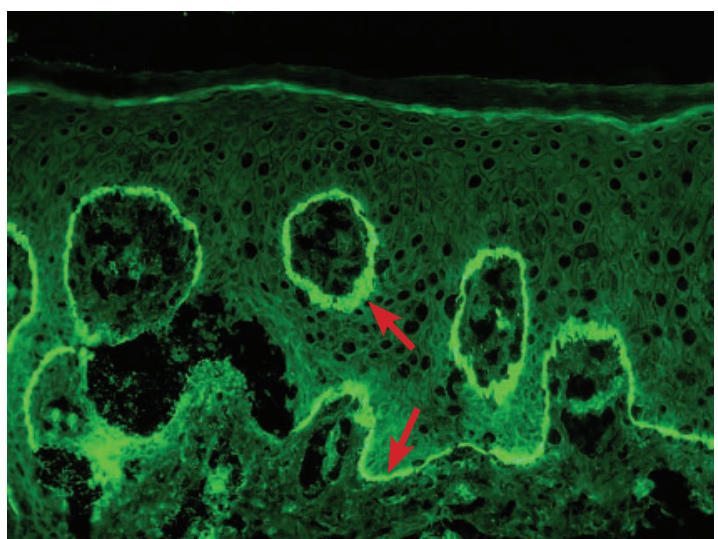

Figure 4. Immunofluorescence showed linear immunoglobulin G and C3 at the dermoepidermal junction (arrows).

simplex virus (HSV) 1 and 2, varicella, and enterovirus using viral skin swabs from her left hand. Viral swabs from the lip lesions were negative for HSV.

A skin biopsy of the left hand showed subepidermal bullae with numerous neutrophils in the superficial dermis (Figure 3). A second skin biopsy, on direct immunofluorescence testing, showed linear immunoglobulin G $(\mathrm{IgG})$ and $\mathrm{C} 3$ at the dermoepidermal junction (Figure 4).

\section{DIFFERENTIAL DIAGNOSIS}

What is the most likely cause of this patient's symptoms?

\section{Atypical coxsackievirus infection}

Recurrent herpes virus

Bullous pemphigoid

Epidermolysis bullosa acquisita

The skin biopsy results showing linear IgG and C3 on direct immunofluorescence confirmed a diagnosis of bullous pemphigoid.

Bullous pemphigoid is the most common autoimmune bullous dermatosis, affecting individuals with a median age of $70.1^{1}$ The pathogenesis involves formation of IgG autoantibodies against BP180 and BP230, which are components of hemidesmosomes that maintain dermoepidermal adhesion in stratified epithelia. ${ }^{2}$

Clinical features include tense bullae, often accompanied by erythematous or urticarial plaques on the abdomen, flexor surfaces of 
the extremities, axillae, or inguinal folds that may persist for days before developing erosions and crusts. Blisters may be preceded by an intensely pruritic prodrome, ${ }^{1}$ although this does not develop in at least 20\% of cases. ${ }^{3}$ Mucosal involvement, as seen in this patient, occurs in $10 \%$ to $20 \%$ of patients. ${ }^{1}$

The technical standard for diagnosis is direct immunofluorescence revealing linear IgG or C3 deposits, or both, at the dermoepidermal junction on skin biopsy, though indirect immunofluorescence testing and enzyme-linked immunosorbent assay detection of BP180 or BP230 antibodies may help with the diagnosis. ${ }^{4}$

The most likely causes of our patient's bullous pemphigoid are discussed in the following sections.

\section{DRUG-INDUCED BULLOUS PEMPHIGOID}

More than 50 medications have been associated with the development of bullous pemphigoid, including etanercept, sulfasalazine, furosemide, and penicillin..$^{5-7}$ Drug-induced bullous pemphigoid may present acutely and resolve quickly after the offending agent is removed, or it may follow a chronic course that resembles idiopathic bullous pemphigoid. In either case, symptoms may develop up to 3 months after the medication was started. ${ }^{8}$

Although losartan has been linked to bullous pemphigoid in a single case, ${ }^{9}$ loop diuretics such as furosemide are among the most commonly reported culprits. ${ }^{5}$ There seems to be no association with the dose of furosemide and development of bullous pemphigoid, with doses in case reports ranging from 40 to 120 mg daily. ${ }^{10}$

Because there are no known antibodies specific to drug-induced bullous pemphigoid, ${ }^{11,12}$ it is possible that our patient coincidentally developed idiopathic bullous pemphigoid in the setting of furosemide therapy. However, her lesions improved after we stopped her furosemide while continuing losartan (see Management), supporting furosemide as the causative agent.

A 2020 systematic review found that in addition to loop diuretics, other agents with the greatest evidence supporting their role in drug-induced bullous pemphigoid are dipep- tidyl peptidase 4-inhibitors (gliptins), inhibitors of programmed cell death protein 1 and programmed cell death ligand 1 , and penicillin derivatives. ${ }^{13}$

\section{Histopathology}

Light microscopy of bullous pemphigoid lesions typically reveals subepidermal blisters with an eosinophil-rich superficial dermal infiltrate. ${ }^{1}$ Neutrophilic infiltrates, as seen in this patient's biopsy, are rarely reported in bullous pemphigoid, and they are more typically associated with other bullous diseases such as linear IgA bullous dermatosis and dermatitis herpetiformis. ${ }^{14}$ Nonetheless, in this patient, the absence of linear IgA deposits at the dermoepidermal junction on immunofluorescence ruled out linear IgA bullous dermatosis. ${ }^{15}$

Although BP180 and BP230 antibodies were not detected in her serum, about $8 \%$ of bullous pemphigoid cases do not have significant levels of circulating BP180 autoantibodies, ${ }^{16}$ and $8 \%$ of people without bullous pemphigoid test positive for 1 or both autoantibodies. ${ }^{17}$

\section{COXSACKIEVIRUS INFECTION}

Coxsackievirus A16, a nonpolio enterovirus, causes hand, foot, and mouth disease (HFMD). This disease is most common in children under 5 years of age, but it may affect older children and adults.

Cases classically manifest as an oral enanthem or a nonpainful, nonpruritic exanthem of the hands, feet, buttocks, thighs, and arms. The enanthem is characterized by erythematous macules that progress to vesicles on erythematous bases before ultimately ulcerating. The exanthem may be macular, maculopapular, or vesicular, and most commonly arises on the dorsum of the hands and feet, occasionally affecting the palms and soles.

The diagnosis is clinical in children but may be confirmed by biopsy in adults, for whom the differential diagnosis is more extensive owing to consideration of autoimmune bullous diseases. Biopsy of HFMD lesions typically reveals loose strands of fibrin, lymphocytes, monocytes, and neutrophils with acantholysis of the epidermis. ${ }^{18}$

In the past decade, outbreaks of so-called
Topical steroids applied to the entire body except the face often suffice in mild, localized bullous pemphigoid regardless of the cause 
atypical HFMD have been documented in adults with coxsackievirus A6. In contrast to typical HFMD, skin lesions in atypical HFMD are painful, are distributed more widely across the body, and may include bullae and eschar formation. Biopsy of atypical HFMD skin lesions reveals intense edema, necrotic keratinocytes, and neutrophilic exocytosis with T-cell infiltrate. ${ }^{19}$ In our patient's case, biopsy results were not consistent with either typical or atypical coxsackievirus.

\section{HERPES VIRUS INFECTION}

Given this patient's oral lesions and history of herpes labialis, erythema multiforme arising from HSV infection was included in the differential diagnosis. Herpes labialis typically presents as painful ulcerations at the vermilion border or the buccal mucosa that last up to 8 days and may be preceded by a painful or pruritic prodrome. It may be complicated by erythema multiforme, a self-limited cutaneous autoimmune disease characterized by targetoid lesions with 2 or 3 different concentric zones, with or without bullae formation in the center zone.

Erythema multiforme most commonly arises from HSV infection, but it may also be caused by drug reaction or other infectious pathogens including Mycoplasma pneumoniae, hepatitis $C$ virus, Epstein-Barr virus, or coxsackievirus. Histologic features of erythema multiforme vary depending on the cause of the disease, site of biopsy within the skin lesion, and time point of biopsy in the disease course, but they generally include spongiosis, keratinocyte necrosis, and inflammatory infiltrate at the dermoepidermal junction. ${ }^{20}$ In patients with HSV-associated erythema multiforme, HSV DNA is detected in $43 \%$ of lesional skin biopsies. ${ }^{21}$ It was not detected in our patient's skin lesions.

\section{EPIDERMOLYSIS BULLOSA ACQUISITA}

Epidermolysis bullosa acquisita (EBA) is a rare autoimmune blistering disorder characterized by the production of autoantibodies against type VII collagen, which anchors fibrils at the dermoepidermal junction and provides stability to structures in the extracellular matrixes. The clinical presentation varies but classically involves skin fragility and the formation of trauma-induced, noninflammatory, tense bullae in an acral distribution, with or without mucosal involvement. ${ }^{22}$

A subtype of EBA known as bullous pemphigoid-like EBA, which presents with tense bullae surrounded by inflamed or urticarial skin, was considered in this patient's differential diagnosis given the skin lesions on her hands.

Up to $50 \%$ of patients with EBA have a bullous pemphigoid-like presentation, and in a review of sera from 85 patients diagnosed with bullous pemphigoid, $10 \%$ of bullous pemphigoid patients had circulating EBA antibodies. ${ }^{23}$ In our patient, the negative results for collagen type VII IgG antibodies excluded a diagnosis of EBA.

\section{MANAGEMENT}

2

What is the best next step in treating this patient's bullous lesions?

Topical tacrolimus

Oral corticosteroids

Dapsone

Tetracycline plus nicotinamide

Discontinue furosemide

Furosemide was discontinued, and the patient was prescribed triamcinolone $0.1 \%$ cream to use on an outpatient basis. One month after discharge, she had only 2 urticarial plaques, and she was completely clear 2 months later.

Treatment with topical corticosteroids applied to affected areas and avoiding the face is often sufficient in mild, localized bullous pemphigoid regardless of the cause. Tapering the steroid dose may begin after 15 days of disease control, defined as the time point at which new bullous lesions and pruritus cease to form and existing lesions begin to heal, with a total treatment duration of 4 to 12 months. Supportive skin care such as baths containing antiseptics or wheat starch, or both, and application of nonadherent dressings to erosive lesions may improve the patient's comfort, reduce bacterial infection, and promote wound healing. ${ }^{24}$ No large-scale clinical trial has evaluated the safety and efficacy of topical tacrolimus in bullous pemphigoid.

Severe or recurrent disease may warrant 
use of oral steroids, tetracyclines plus nicotinamide, dapsone, or immunosuppressive agents, and should be supervised by a dermatologist. ${ }^{24}$ In patients with drug-induced bullous pemphigoid, such as our patient, the suspected causative drug should be discontinued immediately. ${ }^{5}$

As a substitute for furosemide to treat her hypertension, the patient's losartan dose was increased to $100 \mathrm{mg}$ daily, and she was also prescribed amlodipine $10 \mathrm{mg}$ daily and hydralazine 50 mg every 8 hours, with plans for close follow-up with her primary care physician. At discharge, her blood pressure had improved but remained elevated at $150 / 75 \mathrm{~mm}$ $\mathrm{Hg}$. There is not enough literature available to guide the choice of an alternative to loop diuretics in patients with a history of furosemide-induced bullous pemphigoid.

\section{FOLLOW-UP}

3

Patients with bullous pemphigoid are more likely than patients without the disease to develop which of the following morbidities?

Kidney disease

Neurologic disorders

Malignancy

Heart disease

Our patient was found to have Alzheimer dementia 4 months after developing bullous pemphigoid, consistent with the documented association between bullous pemphigoid and neurologic disorders including dementia, stroke, epilepsy, Parkinson disease, and multiple sclerosis. ${ }^{25-27}$ While the mechanism of this association is unclear, immunologic crossreactivity of antibodies targeting the $\mathrm{BP} 230$ isoforms in both the epidermis and brain may play a role. ${ }^{28,29}$

Retrospective studies have detected a higher rate of bullous pemphigoid in patients with laryngeal and renal cancers, as well as hematologic malignancies. ${ }^{30,31}$ However, a recent systematic review and meta-analysis that included these studies did not identify an association between bullous pemphigoid and malignancy. ${ }^{32}$

Although patients with bullous pemphigoid have more frequent hospitalizations and comorbidities, ${ }^{33,34}$ there is no documented association between bullous pemphigoid and heart or kidney disease in particular.

\section{TAKE-HOME POINTS}

- If bullae develop in a patient taking furosemide, consider drug-induced bullous pemphigoid.

- Bullous pemphigoid is diagnosed by a medical history, physical examination, and skin biopsy for evaluation by light microscopy and immunofluorescence.

- In treating drug-induced bullous pemphigoid, stop the causative drug immediately, and apply topical corticosteroids.

- Bullous pemphigoid is associated with neurologic disorders, including dementia.

Acknowledgments: The authors acknowledge and thank the patient discussed in this report.

\section{DISCLOSURES}

The authors report no relevant financial relationships which, in the context of their contributions, could be perceived as a potential conflict of interest.

\section{REFERENCES}

1. Schmidt E, della Torre R, Borradori L. Clinical features and practical diagnosis of bullous pemphigoid. Dermatol Clin 2011; 29(3):427438. doi:10.1016/j.det.2011.03.010

2. Di Zenzo G, Della Torre R, Zambruno G, Borradori L. Bullous pemphigoid: from the clinic to the bench. Clin Dermatol 2012; 30(1):3-16. doi:10.1016/j.clindermatol.2011.03.005

3. Lamberts A, Meijer JM, Jonkman MF. Nonbullous pemphigoid: a systematic review. J Am Acad Dermatol 2018; 78(5):989-995.e2. doi:10.1016/j.jaad.2017.10.035

4. Sárdy M, Kostaki D, Varga R, Peris K, Ruzicka T. Comparative study of direct and indirect immunofluorescence and of bullous pemphigoid 180 and 230 enzyme-linked immunosorbent assays for diagnosis of bullous pemphigoid. J Am Acad Dermatol 2013; 69(5):748-753. doi:10.1016/j.jaad.2013.07.009

5. Stavropoulos PG, Soura E, Antoniou C. Drug-induced pemphigoid: a review of the literature. J Eur Acad Dermatol Venereol 2014; 28(9):1133-1140. doi:10.1111/jdv.12366

6. Patsatsi A, Vyzantiadis TA, Chrysomallis F, Devliotou-Panagiotidou D, Sotiriadis D. Medication history of a series of patients with bullous pemphigoid from northern Greece-observations and discussion. Int J Dermatol 2009; 48(2):132-135. doi:10.1111/j.1365-4632.2009.03839.x

7. Lloyd-Lavery A, Chi CC, Wojnarowska F, Taghipour K. The associations between bullous pemphigoid and drug use: a UK case-control study. JAMA Dermatol 2013; 149(1):58-62 doi:10.1001/2013.jamadermatol.376

8. Lee JJ, Downham TF 2nd. Furosemide-induced bullous pemphigoid: case report and review of literature. J Drugs Dermatol 2006; 5(6):562-564. pmid:16774111

9. Saraceno R, Citarella L, Spallone G, Chimenti S. A biological approach in a patient with psoriasis and bullous pemphigoid associ- 
ated with losartan therapy. Clin Exp Dermatol 2008; 33(2):154-155. doi:10.1111/j.1365-2230.2007.02603.x

10. Baz K, Ikizoglu G, Kaya TI, Koca A. Furosemide-induced bullous pemphigoid. J Eur Acad Dermatol Venereol 2002; 16(1):81-82. doi:10.1046/j.1468-3083.2002.383_1.x

11. Kashihara M, Danno K, Miyachi Y, Horiguchi Y, Imamura S. Bullous pemphigoid-like lesions induced by phenacetin. Report of a case and an immunopathologic study. Arch Dermatol 1984; 120(9):11961199. pmid:6383223

12. Smith EP, Taylor TB, Meyer LJ, Zone JJ. Antigen identification in drug-induced bullous pemphigoid. J Am Acad Dermatol 1993; 29(5 pt 2):879-882. doi:10.1016/0190-9622(93)70262-r

13. Verheyden MJ, Bilgic A, Murrell DF. A systematic review of druginduced pemphigoid. Acta Derm Venereol 2020; 100(15):adv00224. Published August 17, 2020. doi:10.2340/00015555-3457

14. Farmer ER. Subepidermal bullous diseases. J Cutan Pathol 1985; 12(3-4):316-321. doi:10.1111/j.1600-0560.1985.tb01635.x

15. Guide SV, Marinkovich MP. Linear IgA bullous dermatosis. Clin Dermatol 2001; 19(6):719-727. doi:10.1016/s0738-081x(00)00185-1

16. Fairley JA, Bream M, Fullenkamp C, Syrbu S, Chen M, Messingham KN. Missing the target: characterization of bullous pemphigoid patients who are negative using the BP180 enzyme-linked immunosorbant assay. J Am Acad Dermatol 2013; 68(3):395-403. doi:10.1016/j.jaad.2012.09.012

17. Wieland CN, Comfere NI, Gibson LE, Weaver AL, Krause PK, Murray JA. Anti-bullous pemphigoid 180 and 230 antibodies in a sample of unaffected subjects. Arch Dermatol 2010; 146(1):21-25. doi:10.1001/archdermatol.2009.331

18. Miller GD, Tindall JP. Hand-foot-and-mouth disease. JAMA 1968; 203(10):827-830. pmid:5694203

19. Second J, Velter C, Calès S, Truchetet F, Lipsker D, Cribier B. Clinicopathologic analysis of atypical hand, foot, and mouth disease in adult patients. J Am Acad Dermatol 2017; 76(4):722-729. doi:10.1016/j.jaad.2016.10.022

20. Lerch M, Mainetti C, Terziroli Beretta-Piccoli B, Harr T. Current perspectives on erythema multiforme. Clin Rev Allergy Immunol 2018; 54(1):177-184. doi:10.1007/s12016-017-8667-7

21. Ng PP, Sun YJ, Tan HH, Tan SH. Detection of herpes simplex virus genomic DNA in various subsets of erythema multiforme by polymerase chain reaction. Dermatology 2003; 207(4):349-353. doi:10.1159/000074112

22. Komorowski L, Müller R, Vorobyev A, et al. Sensitive and specific assays for routine serological diagnosis of epidermolysis bullosa acquisita. J Am Acad Dermatol 2013; 68(3):e89-e95. doi:10.1016/j.jaad.2011.12.032

23. Gammon WR, Briggaman RA, Woodley DT, Heald PW, Wheeler CE Jr. Epidermolysis bullosa acquisita-a pemphigoid-like disease. J Am
Acad Dermatol 1984: 11(5 pt 1):820-832 doi:10.1016/s0190-9622(84)80459-4

24. Feliciani $\mathbf{C}$, Joly $\mathbf{P}$, Jonkman MF, et al. Management of bullous pemphigoid: the European Dermatology Forum consensus in collaboration with the European Academy of Dermatology and Venereology. Br J Dermatol 2015; 172(4):867-877. doi:10.1111/bjd.13717

25. Bastuji-Garin $\mathbf{S}$, Joly $\mathbf{P}$, Lemordant $\mathbf{P}$, et al. Risk factors for bullous pemphigoid in the elderly: a prospective case-control study. J Invest Dermatol 2011; 131(3):637-643. doi:10.1038/jid.2010.301

26. Jedlickova H, Hlubinka M, Pavlik T, Semradova V, Budinska E, Vlasin Z. Bullous pemphigoid and internal diseases-a case-control study. Eur J Dermatol 2010; 20(1):96-101. doi:10.1684/ejd.2010.0805

27. Langan SM, Groves RW, West J. The relationship between neurological disease and bullous pemphigoid: a population-based casecontrol study. J Invest Dermatol 2011; 131(3):631-636. doi:10.1038/jid.2010.357

28. Brown A, Bernier G, Mathieu M, Rossant J, Kothary R. The mouse dystonia musculorum gene is a neural isoform of bullous pemphigoid antigen 1. Nat Genet 1995; 10(3):301-306 doi:10.1038/ng0795-301

29. Li L, Chen J, Wang B, Yao Y, Zuo Y. Sera from patients with bullous pemphigoid (BP) associated with neurological diseases recognized BP antigen 1 in the skin and brain. Br J Dermatol 2009; 160(6):13431345. doi:10.1111/j.1365-2133.2009.09122.x

30. Ong E, Goldacre R, Hoang U, Sinclair R, Goldacre M. Associations between bullous pemphigoid and primary malignant cancers: an English national record linkage study, 1999-2011. Arch Dermatol Res 2014; 306(1):75-80. doi:10.1007/s00403-013-1399-5

31. Schulze F, Neumann K, Recke A, Zillikens D, Linder R, Schmidt E. Malignancies in pemphigus and pemphigoid diseases. J Invest Dermatol 2015; 135(5):1445-1447. doi:10.1038/jid.2014.547

32. Atzmony L, Mimouni I, Reiter O, et al. Association of bullous pemphigoid with malignancy: a systematic review and meta-analysis. J Am Acad Dermatol 2017; 77(4):691-699. doi:10.1016/j.jaad.2017.05.006

33. Ren Z, Hsu DY, Brieva J, Silverberg NB, Langan SM, Silverberg J. Hospitalization, inpatient burden and comorbidities associated with bullous pemphigoid in the USA. Br J Dermatol 2017; 176(1):87-99. doi:10.1111/bjd.14821

34. Sim B, Fook-Chong S, Phoon YW, et al. Multimorbidity in bullous pemphigoid: a case-control analysis of bullous pemphigoid patients with age- and gender-matched controls. J Eur Acad Dermatol Venereol 2017; 31(10):1709-1714. doi:10.1111/jdv.14312

Address: Karthik Gnanapandithan, MD, Department of Internal Medicine, Mayo Clinic, 4500 San Pablo Rd S, Jacksonville, FL, 32224; gnanapandithan.karthik@mayo.edu 